\section{ANOTHER CASE OF IMPACTION OF A GALL-STONE IN THE LARGE INTESTINE; LAPAROTOMY; RECOVERY.}

By F. VICTOR MILWARD, M.B., B.C. CANTAB., F.R.C.S. ENG.,

SURGICAL CASUALTY OFFICER TO THE GENERAL HOSPITAL, BIRMINGHAM; SURGEON TO OUT-PATIENTE AT THE CHILDREN'S HOSPTTAL, BIRMINGHAM.

THE publication by Mr. S. Maynard Smith in THE LANCET of Oct. 21st, p. 1174, of the late Mr. A. Q. Silcock's case of impaction of a gall-stone in the large intestine induces me to relate a very similar case which has recently occurred in my own practice; it had, indeed, been my intention to send my case for publication before reading the one just alluded to.

The patient, a thin and decrepit woman, 67 years of age, was admitted to the General Hospital, Birmingham, under the care of Mr. H. G. Barling, on July 27th, 1905, suffering from fairly acute symptoms of intestinal obstruction which had existed for four days. During this time she had vomited several times but had not done so for 36 hours before admission. The bowels had not been opened but she had passed a little flatus. Precise particulars of this and of previous illness were very difficult to obtain but $I$ have since ascertained that the patient had been fairly well up to the time of this attack, that she had not suffered from pain or other symptoms attributable to gall-stones, that the bowels had been nearly always regular, and that only on rare occasions had she taken salts. There seems to be no history of any illness, such as one would have expected from the ulceration of a gall-stone into the intestine.

On examination the abdomen, especially on the left side, was seen to be largely distended, so much so indeed that had it not been that the symptoms had existed for some days and were not hyperacute, a diagnosis of volvulus would have been made. As a matter of fact much of this distension was afterwards found to be due to an atonic condition of the muscular parietes and the accumulation of intra-abdominal fat.

I operated in 'Mr. Barling's absence and under an anæsthetic at once discovered a hard, moveable mass in the left iliac fossa, its previous recognition having been obscured by the distension and rigidity. The case appeared now to be plainly one of carcinoma of the sigmoid flexure and suitable either for colostomy or short-circuiting. An incision was made as for Littré's operation and upon pulling up the sigmoid flexure the supposed carcinoma resolved itself into a normal portion of the large intestine which was tightly gripping a hard body in its lumen. The appearance is very well portrayed by the illustration in Mr. Maynard Smith's article. As it did not appear feasible to move the foreign body or to break it up in situ I decided to remove it by an incision through the gut wall. By carrying the knife along the longitudinal band opposite to the mesenteric border and cutting on to the enclosed body the calculus was exposed and turned out. Owing to the friability of the tissues it was found somewhat difficult to repair the aperture. This was finally accomplished, after Lembert's sutures had failed to hold, by a single row of stitches through all the coats of the intestine and the utilisation of such appendices epiploice as could be brought to cover the area. The abdominal wound was now completely closed, without the employment of a drain. For some days afterwards the patient was in a very precarious condition, suffering much from bronchitis, for which she had to be propped up in bed, and also from severe mental and physical depression. The bowels gave some difficulty during the first few days and to obtain an evacuation I employed glycerine enemata with small doses of salts and calomel rather than large injections per anum, which would possibly have wrought damage to the intestinal wound. Notwithstanding the constant cough, the abdominal wound gave very little trouble. About the end of the first week the patient picked up rapidly, put on flesh, and became much brighter and happier. She was finally discharged in comparatively good health on the twenty-seventh day after the operation. At the present time, three months later, she lies in the workhouse infirmary in a senile "mithering" condition with her thoughts concentrated on a painful ulcer of ber leg. She has quite forgotten her past abdominal troubles.

Particulars of the calculus are as follows, Its weight is 465 grains. It is ovoid in shape, having the usual contour of the single large stones sometimes met with in the gallbladder. It possesses no facets. By measurement the length is $1 \frac{5}{8}$ inches, the breadth $1 \frac{1}{8}$ inches, and the circumference $3_{4}^{1}$ inches. It is composed of concentric laminæ of dark brown and greyish white material, the external hue being a rich reddish brown. Dr. J. H. Rhodes of the University of Birmingham, who has kindly made an analysis, tells me that it is composed of an inorganic basis, chiefly made up of magnesium carbonate-roughly from 25 to 30 per cent. of the whole. There is plenty of cholesterine present and this appears to be generally distributed through the concretion. Bile pigments and organised débris are also present in considerable amount.

The presence of a comparatively large amount of carbon-te of magnesium points to the possibility of the calculus having been supplemented in the intestine by the addition of that salt taken as a medicine. Both the patient herself and her daughter-in-law, with whom she has lived, are, however, both very positive that salts have very rarely been taken-in fact, the patient much dislikes taking them. Notwithstanding, therefore, that no previous history of gall-stone trouble is available there seems to me to be no doubt that the entire calculus originated from the gall-bladãer and reached the gut by direct ulceration into the large intestine. Had it passed in the first place into the small intestine it seems improbable that it should stick in the sigmoid flexure after safely traversing the ileo-cæcal region. I cannot vouchsafe for the presence of adhesions about the gall-bladder as I did not examine that region at the time of the operation.

Birmingham.

\section{MALIGNANT (?) TUMOUR OF THE RIGHT HYPOCHONDRIUM ; LUMBAR INCISION FOLLOWED BY LAPAROTOMY ; RECOVERY, WITH CURE.}

By F. W. Forbes-Ross, M.D. EdIN., F.R.C.S. ENG.

THE following case must be sufficiently rare in itself and also in its difficulties of diagnosis and results as to line of treatment to be worthy of being placed on record in that it $i_{s}$ the outcome of two abnormal existing conditions in the alodomen.

The patient, a female, aged 35 years, married, weighing 7 stones 10 pounds, was the subject of extreme emaciation; she was anæmic and pasty, apparently showing signs of a well-marked and advanced cachexia. There was no icterus. Freqnency of micturition was present with a trace of albumin and a little sugar in the urine. On examination it was possible to palpate an irregularly ovoid botryoidal hard tumour in the right hypochondrium of about the size of a small cocoanut. The tumour was moveable in the abdomen and was replaceable in the loin and when replaced remained there; it was moveable with respiration and manually could be displaced towards the middle line of the abdomen as well as upwards and downwards. It, however, appeared to be attached deeply in the region of the right crura of the diaphragm. The colon resonance was clearly in front of the tumour and the hepatic flexure appeared to separate it from a small, proptosed liver. In the genu-pectoral position the loin appeared hollowed out and empty when the tumour fell forwards. Careful investigation clearly showed it to be unconnected with the bowel or gall-bladder. The liver did not move with respiration and presented no irregularity of its anterior margin and there were no friction sounds.

The patient complained of constant dragging, dull pain in the side and loin, radiating downwards towards the right iliac region. The tumour had been steadily enlarging. She had been refused operative interference on a previous occasion and according to her account was told that it was a growth of a bad nature connected with her kidney too advanced in her delicate state of health to justify operation. She had had some specific treatment accompanied by iron and 
arsenic without any avail and as she was getting rapidly worse and was insistent on something being done for her I decided to cut down and to explore the tumour with a view to removal if possible. A provisional diagnosis was made that the mass was a malignant albuminuria of the suprarenal capsule, which had not materially manifested itself by concomitant well-marked urinary symptoms other than albumin. uria and frequency of micturition. The temperature ranged from $100.4^{\circ}$ to $101.2^{\circ} \mathrm{F}$., and as there were no blood or pus in the urine and no obvious signs of disease in the iungs it was decided after consultation to make an exploratory incision in the loin in lieu of my first intention of approach. ing the tumour through the peritoneal cavity, which latter piocedure appeared to me to offer better facilities of dealing with the condition present and suspected.

On April 28th the patient was put under gas and ether and an incision was made in the right loin with the object of dealing with the supposed renal disease. On exploration of the renal space there was no kidney to be found as its usual position was vacant. Exploration towards the middle line in search of a horse-shoe kidney was negative so the wound was extended forwards towards the outer border of the right rectus and the hand, passed down behind the peritoneum, discovered the kidney lying on the right brim of the pelvis. The tumour was now evidently in the abdominal cavity, having the ascending mesocolon reflected round its outer and anterior surface. The lumbar incision was temporarily plugged with gauze, the patient was turned on her back, and the abdomen was opened in the right linea semilunaris by an incision five inches long. The following condition was now apparent. The anterior surface of the right lobe of the liver and a part of the left were adherent to the abdominal wall. The hepatic flexure of the colon was long, sigmoid, and adherent to the edge and anterior surface of the right lobe of the liver and to the anterior abdominal wall, thus interposing its resonance between the tumour and the liver proper and apparently determining its non-connexion with the liver. The aâhesions were carefully separated and the tumour being reached it was found to be an adventitious outgrowth of the po:terior border and under surface of the right lobe of the liver, attached thereto by a broad, soft, pliable stalk of hepatic tissue. The whole liver was soft and jelly-like and gave the sensation of handling omentum. The right lobe and tumour were gently dragged out of the abdomen as far as possible with a view to remove the tumour by the galvano-cautery, but as the disease involved the whole of the posterior border of the liver and its connexion with the vena cava it was deemed inadvisable to interfere with it further. Careful examination of the condition and the absence of any signs of a primary malignant growth anywhere else in the abdomen after careful search, it was decided that appearances tended to support a specific causation, mainly affecting the moveable part of the right lobe of the liver. The abtomen was therefore closed in three layers and the loin was closed by deep retaining chromic gut sutures (van Horn and Sdwtell's), also fixing the kidney, and the patient was returned to bed after a saline injection into the rectum and a hypodermic of strychnine.

'The patient bore the operation well and had five hours' continuous sleep on the first night. After this she made an uneventful and uninterrupted recovery from the operation, both wounds healing by tirst intention. On the second day alter the operation rectal injections of iodide of potassium, 20 grains each three times a day in two ounces of saline solution, were continued for three weeks, as well as mercury by the mouth, pushed to its utmost limit. Being unable to assimilate iron in any form she was placed on half an ounce of ovoferrin solution thrice daily and quickly gained flesh and strength, the tumour rapidly beginning to disappear, till at the date of her discharge from hospital on July 10th it was only palpable as a small mass of the size of a hen's egg. She weighed $10 \frac{1}{2}$ stones, looked well, and expressed herself so and free from all pain and discomfort, and apparently quite restored to health.

Remarks. - The special points of interest in this case are the previous failure of specific treatment to effect even temporary improvement; the rapid result of iodide of potassium when the whole dose administered was allowed to pass through the entire p rtal system instead of only through the gastric portion; the rapid improvement, in gain in weight, blood counts, and general health, under the additional influence of an organic iron preparation which did not interfere with digestion; the simultancous existence of an ectopic kidney and a diseased outgrowth from the liver occupying the normal position of the kidney, giving its clinical features on examination, aided in this by the peculiar adhesion of the colon; and finally, the kidney itself lower down giving rise to slight renal manifestations, as albuminuria and frequency of micturition and some undoubted renal reflex pain, due no doubt to its abnormal position.

Harley-street, w.

\section{CEREBRO-SPINAL FEVER.}

\section{BY P. L. BLABER, M.R.C.S. ENG., L.R.C.P. LOND.}

THE occurrence of cerebro-spinal fever in epidemics is well known and its prevalence in Europe and America at the present time makes one fear a similar outbreak in this country. Sporadic cases are by no means rare, but in view of the possibility of an isolated case proving the focus of an epidemic it becomes of the utmost importance to recognise the disease and adopt precautionary measures. The two cases here recorded are illustrative of the toxæmic type of the disease. In one profound toxæmia was indicated by the early appearance of hæmorrhagic spots, great dyspnca, unconsciousness, and rapidly fatal termination. This quite conformed in type with what is kxown as "spotted fever." The name is not a good one for these isolated cases, since spots are usually conspicuous by their absence. In this instance the spots were an early and prominent feature, indicating unusual severity of affection. Fortunately, there has been so far no spread of the disease. The other case was ushered in by convulsions, high fever, and a respiration rate of from 70 to 80 per minute, but it was not until some days had elapsed that meningitic signs became evident. It is specially of interest on account of a rare eye complication. Slight conjunctivitis is a common early sign and was present in both cases ; sometimes it is associated with photophobia and may be intense. The children belonged to middle-class families and were apparently healthy. The following are the notes of the cases.

CASE 1. - This patient was a male infant, aged four and a half months. He was the second child, was breast fed, and was exceptionally well nourished. He was seen by me at midday on Oct. 13th, 1905. He had been a little restless during the previous night and somewhat fretful. There was apparently nothing definite the matter with him. His temperature was $101 \cdot 4^{\circ} \mathbf{F}$; he was pale, had dark rings under the eyes, looked ill, and the abdomen was somewhat distended. After a dose of castor oil the bowels acted freely. In the evening his temperature was $102 \cdot 4^{\circ}$, breathing was rapid, the eyes showed slight conjunctivitis, he was crging at intervals, and he was in a semi-stuporous condition. A small bright red hæmorrhagic spot had also appeared on the right shoulder. During the night he was restless and cried frequently. He took the breast once but vomited almost immediately. Next morning his condition was still worse-the stupor and dyspncea were more marked, the conjunctivæ were more suffused, and several fresh spots had appeared on both thighs and the lower part of the abdomen; the temperature had fallen to $101^{\circ}$. In view of a possibility of the case being one of cerebro-spinal fever Dr. E. Cautley was called in to see the child in consultation and agreed with the diagnosis. At this time (12 o'clock noon) the crying was continuous and the child objected to being moved or having the head altered in position; the pupils were small and unequal, the right pupil being greater than the left. A few more spots had become evident and the dyspnœa was more pronounced. There were no definite rigidity of the neck muscles, no tache cérébrale, and no evidence of ear or throat trouble. The legs conld almost be straightened when the thighs were llexed. The temperature at this time was $101^{\circ}$ the pulse was 192, and the respirations were from 60 to 72 per minute. The case was regarded as a very severe type and an unfavourable prognosis was given. During the afternoon the child became steadily worse and died at 6 P.M. The temperature had fallen to $99^{\circ}$ and the pulse had gradually become weaker. Death was immediately preceded by a discharge of turbid fluid from the nose, mouth, and left ear. The thighs and back showed extensive, patchy, purplish discolouration and many more spots had come out on the upper part of the back. 